\title{
Cytogenetic effects of oral Contraceptive pills during pregnancy on some aspects of fetus and newborn in mice

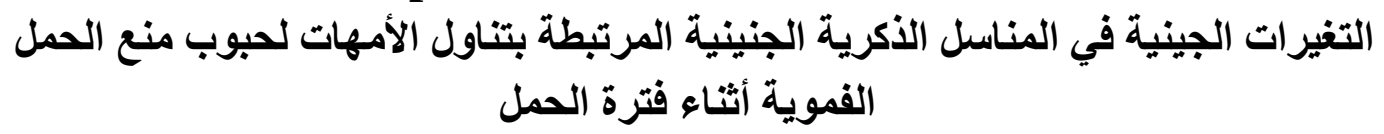

Saeed B.T. $\quad$ Al-Juboori B. M.

Al-Nida S. M.*

High Institute of Infertility Diagnoses and ART/ Al-Nahrain University

*Biotechnology Research Center/ Al-Nahrain University

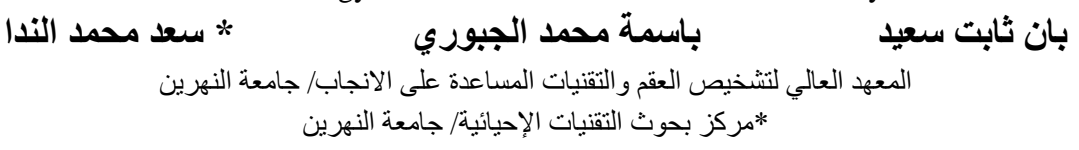

\section{Abstract}

The cytogenetic effects of taking oral contraceptive pills OCPs that contain steroid hormones (estrogen and progesterone) during pregnancy on some aspects of fetus and newborn have been previously reviewed. The objectives of this study are to detect the effect of using different doses of progestin and estrogen by pregnant female mice on the chromosomal aberration CAs and mitotic index MI in their male fetuses. Thirty female mice were divided equally into three major groups: two experimental G1 and G2 and control group according to the level of the dose. Administration of COCPs (either 0.034 or $0.068 \mathrm{mg} / \mathrm{kg} \mathrm{b}$. wt. /d dissolved with $0.1 \mathrm{ml}$ distilled water) orally once a day, were started at the first day of gestation and continued till day 14 for the experimental groups G1and G2 respectively. When the new pups in each experimental and control group reach two weeks of age, those male offspring 10animals/ group were used for chromosome preparation, while the control group divided into two groups: ten animals represented a negative control given distilled water only, while the other ten animals injected intra peritoneal with mitomycin-C $2 \mathrm{mg} / \mathrm{Kg}$ represented positive control (once dose). The statistical analysis of mice bone marrow cells have no significant decrease in the mitotic index of the pups belongs to G1 mothers in comparison with negative control group, but it shows a highly significant differences $P<0.01$ as compared with that of positive control group. Although the pups belong to G2 mothers showed a slight decrease in the mitotic index in comparison with negative control group. Differences were nonsignificant with negative control and highly significant $P<0.01$ with positive control group. In addition, the mitotic index of spleen cells of the pups belongs to G1 mothers noticed no significant decrease in comparison with negative control group, however, it shows a significant differences $P<0.05$ as compared with positive control group. In the pups belongs to G2 mothers there were significant decrease $P<0.05$ in mitotic index in comparison with negative and positive control groups. The results showed that the COCPs caused an increase in chromosomal aberrations CAs with increasing of steroid hormones concentration. In G1 group the CA equal to $19.91 \%$. This reducing in $\mathrm{CA}$ was not significant in comparison with those of the negative control which gave $14.33 \%$; this percentage was increased in the result of CAs of the mice treated with mitomycin -C (MMC) which was 48.58\%. Treatment with 0.068 $\mathrm{mg} / \mathrm{kg} \mathrm{B}$ wt. of COCPs gave CA equal to $17.18 \%$. This value was not significant in Key words: Contraceptive pills, Fetus, Newborn 
comparison with those of the negative control which was $19.91 \%$. Higher doses of OCPs may cause cytogenetic effects in chromosomal aberrations CAs and decrease the mitotic index (MI) in the bone marrow cells and spleen cells of offspring belonged to mothers treated with oral contraceptive during their pregnancy for 14 days.

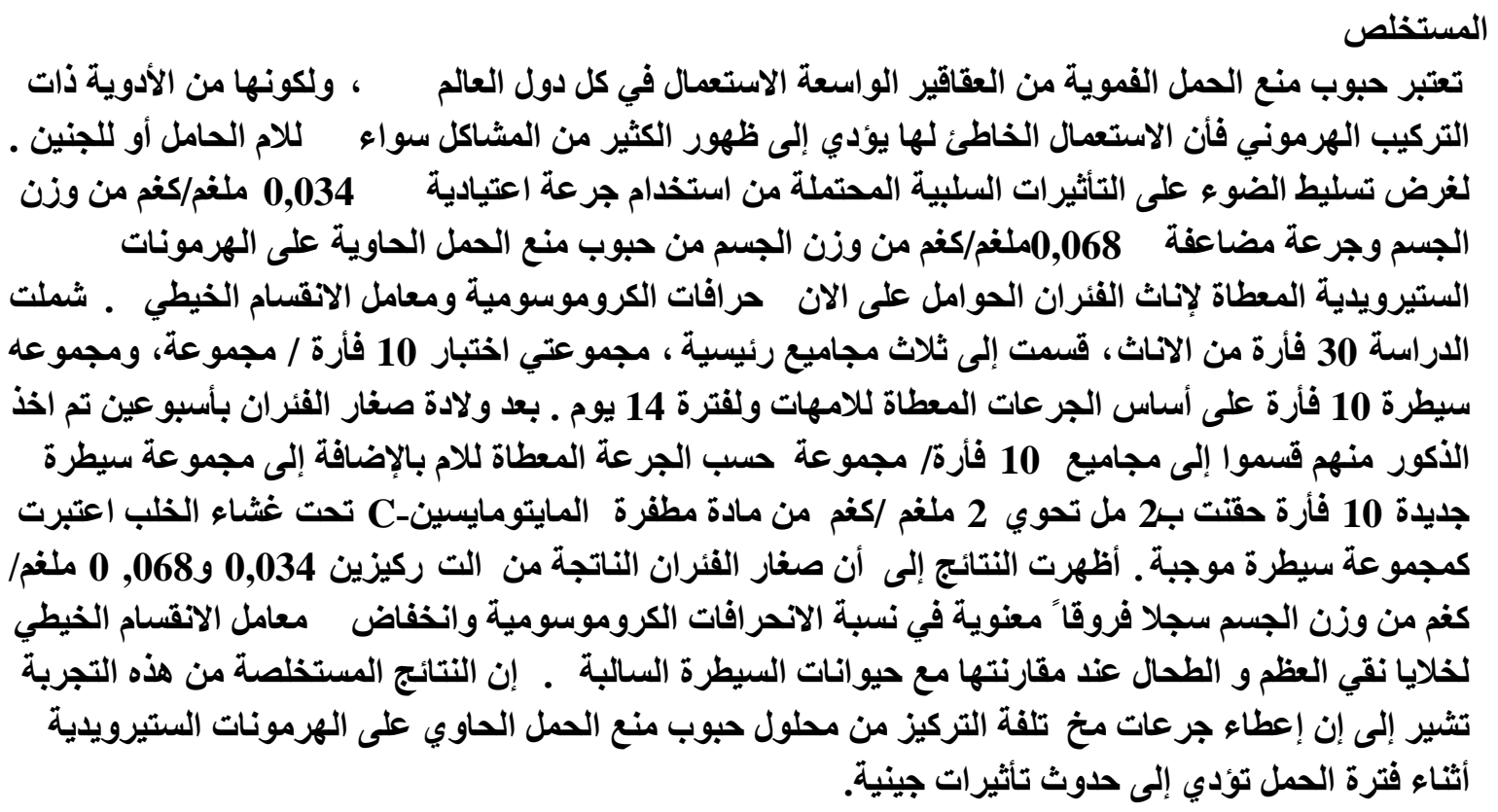

\section{Introduction}

Oral Contraceptive Pills OCPs is a birth control method that includes a combination of an estrogen and a progestin (progestogen). Hormones like those in woman's body, when taken mouthy every day (as pills) inhibit normal female fertility [1]. Oral contraceptives are highly efficient and easily administered drugs; however, they are composed of chemical substances which can be classified as potential carcinogens [2]. Testing of a substance for genotoxicity represents a reliable approach both to evaluate the genetic hazard and to obtain information on its possible tumorigenic (cancerogenic) properties. Reports on the chromosomal effects of oral contraception OC are reviewed [3]. The universal use of OCs by pregnant women age presents a human health problem, for these hormones which are taken continuously for a relatively long time. Due to the fact that the full mechanism of the action of these agents is not totally understood, it is important that the long term genetic effects of OC usage be thoroughly investigated and documented. Some recent publication has suggested that exposure to sex steroids and oral contraceptives OCs during pregnancy may possibly cause congenital defects in human infants exposed in utero [4]. Since estrogens and progestogens are known to affect many metabolic and biochemical systems (it is possible that these substances may induce in OC users and pregnant women, a slightly altered in vivo condition, in which increased chromosome breakages may be expressed). The purpose of this study is to detect the chromosomal aberration in the bone marrow and spleen of the male offspring belonged to mothers that take OCPs during their pregnancy [5] 


\section{Materials and methods}

Thirty female mice were divided equally into three major groups: two experimental G1 and G2 and control group according to the level of the dose 10 animal/ group. Vaginal smears were performed to diagnose the stages of estrus cycle, to detect heat stage for mating. Females in the metestrus phase were left with mature healthy males for mating 1 male/2female. The occurrence of vaginal plug was considered as the first day of pregnancy, the pregnant female was removed into separate cages. Administration of COCPs (either 0.034 or $0.068 \mathrm{mg} / \mathrm{kg}$ b. wt. /d) were dissolved with $0.1 \mathrm{ml}$ distilled water, orally once daily, were started at the first day of gestation and continued for day 14 for the experimental groups G1and G2 respectively, while the two parallel control groups were orally administered with distilled water using the same route and dose in the experimental groups. When the new pups in each experimental and control group reach two weeks of age, those male offspring 10 animals/group belongs to mothers who had taken COCPs during their pregnancy were used for chromosome preparation, while the control group divided into two groups: ten animals represented a negative control given distilled water only, while the other ten animals injected intraperitoneally with mitomycin-C $2 \mathrm{mg} / \mathrm{Kg}$ represented positive control once dose.

\section{Results}

\section{A -Mitotic index (MI)}

1- Bone marrow cells:

The results showed that mice bone marrow cells have no significant decrease in the mitotic index of the pups belongs to G1 mothers $(0.034 \mathrm{mg} / \mathrm{kg} \mathrm{b}$. wt. of COCPs $)$ in comparison with negative control group, but it shows a highly significant differences $\mathrm{P}<$ 0.01 as compared with that of positive control group (which injected intraperitoneally with mitomycin $-\mathrm{C} 2 \mathrm{Kg} / \mathrm{mg}$ one dose) Table (1). Although the new generation of mice whom their mothers treated with $0.068 \mathrm{mg} / \mathrm{kg} \mathrm{b}$. wt. of COCPs showed a slight decrease in the mitotic index in comparison with negative control group. Differences were nonsignificant with negative control and highly significant $\mathrm{P}<0.01$ with positive control group figure (1).

Table (1): mitotic index for the bone marrow cells and spleen cells of the new generation of mice whom mothers were treated with $0.034 \mathrm{mg} / \mathrm{kg}$ B wt. (G1) and $0.068 \mathrm{mg} / \mathrm{kg} \mathrm{B}$ wt. (G2) of COCPs during their pregnancy (Mean \pm S.E.)

\begin{tabular}{|c|c|c|c|c|c|c|c|}
\hline \multirow[t]{2}{*}{$\begin{array}{l}\text { Studied } \\
\text { organs }\end{array}$} & $\begin{array}{c}\text { Experimental } \\
\text { group }\end{array}$ & $\begin{array}{l}\text { Mitotic index } \\
\text { value }\end{array}$ & $\begin{array}{l}\text { Positive c. } \\
\text { vs. } \\
\text { Negative c. }\end{array}$ & $\begin{array}{c}\text { Double } \\
\text { dose vs. } \\
\text { Positive c. }\end{array}$ & $\begin{array}{c}\text { P value } \\
\text { Double } \\
\text { dose vs. } \\
\text { Negative c. }\end{array}$ & $\begin{array}{c}\text { Normal } \\
\text { dose vs. } \\
\text { Positive c. }\end{array}$ & $\begin{array}{c}\text { Normal } \\
\text { dose vs. } \\
\text { Negative c. }\end{array}$ \\
\hline & Negativecontrol & $11.133 \pm 0.612$ & \multirow{4}{*}{$0.006 *$} & \multirow{4}{*}{$\leq 0.001 * *$} & \multirow{4}{*}{$0.090^{\mathrm{NS}}$} & \multirow{4}{*}{$\leq 0.001 * *$} & \multirow{3}{*}{$0.687^{\mathrm{NS}}$} \\
\hline \multirow{4}{*}{$\begin{array}{c}\text { Bone } \\
\text { marrow }\end{array}$} & Positive control & $7.800 \pm 0.115$ & & & & & \\
\hline & Normal dose & $10.833 \pm 0.273$ & & & & & \\
\hline & Double dose & $9.733 \pm 0.145$ & & & & & \\
\hline & Negative control & $5.933 \pm 0.437$ & \multirow{4}{*}{$0.010 *$} & \multirow{4}{*}{$0.050 *$} & \multirow{4}{*}{$0.059 *$} & \multirow{4}{*}{$0.009 *$} & \multirow{4}{*}{$0.162^{\mathrm{NS}}$} \\
\hline \multirow{3}{*}{ Spleen } & Positive control & $3.167 \pm 0.418$ & & & & & \\
\hline & Normal dose & $5.167 \pm 0.088$ & & & & & \\
\hline & Double dose & $4.567 \pm 0.285$ & & & & & \\
\hline
\end{tabular}




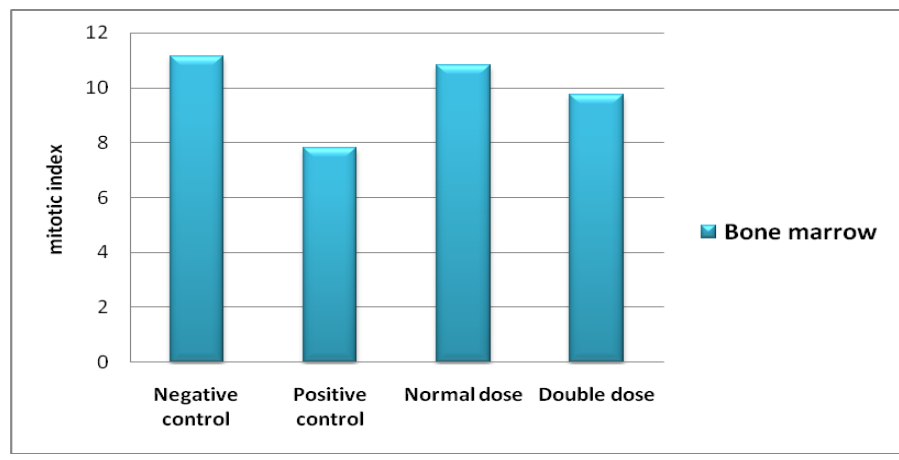

Figure (1): mitotic index for the bone marrow cells of the new generation of mice whom mothers were treated with $0.034 \mathrm{mg} / \mathrm{kg} B$ wt. (G1) and $0.068 \mathrm{mg} / \mathrm{kg} \mathrm{B} \mathrm{wt.} \mathrm{(G2)} \mathrm{of} \mathrm{COCPs} \mathrm{during} \mathrm{their} \mathrm{pregnancy.}$

\section{2-spleen cells:}

The offspring of mice whom mothers treated with $0.034 \mathrm{mg} / \mathrm{kg} \mathrm{b}$. wt. COCPs noticed no significant decrease in mitotic index in comparison with negative control group, however, it showed a significant differences $\mathrm{P}<0.05$ as compared with positive control group table (1). In the double dose group $(0.068 \mathrm{mg} / \mathrm{kg} \mathrm{b}$. wt. of COCPs) there was significant decrease $\mathrm{P}<0.05$ in mitotic index in comparison with negative and positive control group figure (2).

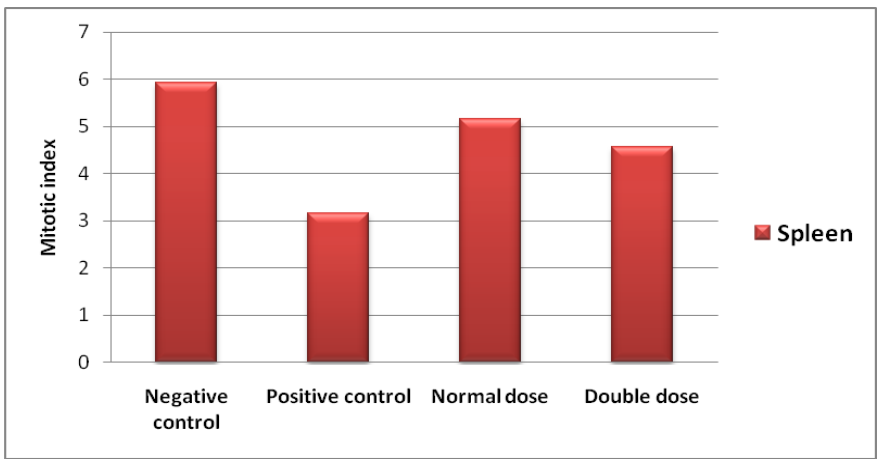

Figure (2): mitotic index for the spleen cells of the new generation of mice whom mothers were treated with $0.034 \mathrm{mg} / \mathrm{kg}$ B wt. (G1) and $0.068 \mathrm{mg} / \mathrm{kg}$ B wt. (G2) of COCPs during their pregnancy.

\section{B -Chromosomal aberration}

The results in table (2) showed that the COCPs caused an increase in chromosomal aberrations CAs with increasing of steroid hormones concentration. In G1 group the CA equal to $19.91 \%$. This reducing in CA was not significant in comparison with those of the negative control which gave $14.33 \%$; this percentage was increased in the result of CAs of the mice treated with mitomycin - $\mathrm{C}$ (MMC) which was $48.58 \%$ as shown in Table (2). Treatment with $0.068 \mathrm{mg} / \mathrm{kg}$ B wt. of COCPs gave CA equal to $17.18 \%$. This value was not significant in comparison with those of the negative control which was $19.91 \%$.

The CAs noticed in this study was breaks, ring, dysenteric and a centric which appeared when using different concentrations of COCPs figure $(3,4)$. 
Table (2): cytogenetic effect of different concentration of COCPs with negative (distilled water) and positive control mitomycin $-\mathrm{C}$ (MMC) on mice bone marrow cells (mean $\pm \mathrm{SE}$ ).

\begin{tabular}{lllllll}
\hline & \multicolumn{3}{c}{ Chromosomal aberration $($ mean \pm SE) $/ 100$ cells } & & \\
Treatment & Breaks & Ring & Dicentric & Acentric & Total & Percentage \\
& & & & & & $\%$ \\
negative control & $\mathbf{1 . 6 6} \pm \mathbf{0 . 0 0 3}$ & --- & $.33 \pm \mathbf{0 . 0 0 1}$ & $\mathbf{0 . 3 3} \pm \mathbf{0 . 0 0 9}$ & $\mathbf{2 . 3 2} \pm \mathbf{0 . 2}$ & $\mathbf{1 9 . 9 0}$ \\
Positive control & $\mathbf{2 . 3 3} \pm \mathbf{0 . 0 0 6}$ & $\mathbf{1 . 3 3} \pm \mathbf{0 . 0 0 3}$ & $\mathbf{0 . 3 3} \pm \mathbf{0 . 0 0 1}$ & $\mathbf{1 . 6 7} \pm \mathbf{0 . 0 0 5}$ & $\mathbf{5 . 6 6} \pm \mathbf{0 . 4}$ & $\mathbf{4 8 . 6 2}$ \\
Normal dose & $\mathbf{1 . 0 0} \pm \mathbf{0 . 0 0 2}$ & --- & $\mathbf{0 . 3 3} \pm \mathbf{0 . 0 0 1}$ & $\mathbf{0 . 3 3} \pm \mathbf{0 . 0 0 1}$ & $\mathbf{1 . 6 6} \pm \mathbf{0 . 0 0 6}$ & $\mathbf{1 4 . 3 0}$ \\
Double dose & $\mathbf{1 . 0 0} \pm \mathbf{0 . 0 0 2}$ & --- & $\mathbf{0 . 3 3} \pm \mathbf{0 . 0 0 1}$ & $\mathbf{0 . 6 7} \pm \mathbf{0 . 0 1}$ & $\mathbf{2 . 0 0} \pm \mathbf{0 . 0 0 3}$ & $\mathbf{1 7 . 1 8}$ \\
\hline
\end{tabular}

Different superscripts within each row differ significantly $(\mathbf{p}<0.05)$.

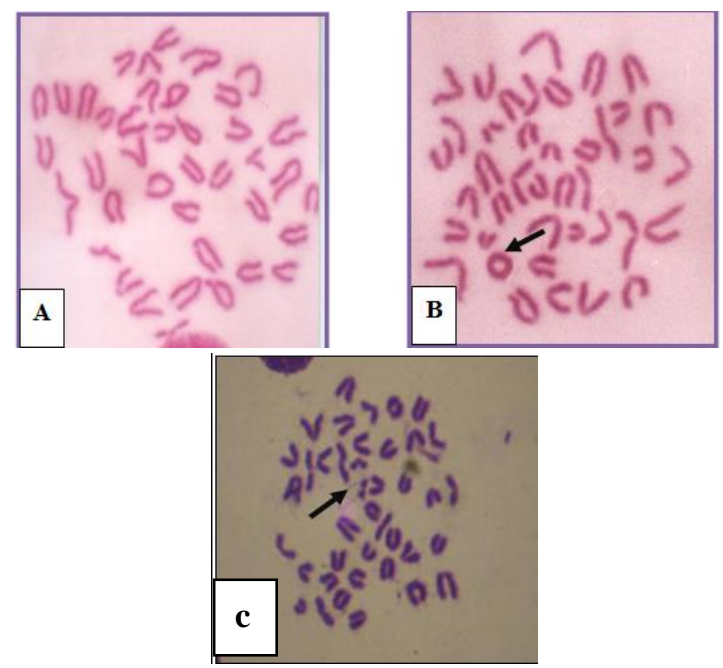

Figure (3): Metaphase spreads of bone marrow cells of mice whom mothers were treated with 0.068 $\mathrm{mg} / \mathrm{kg} \mathrm{B}$ wt. of COCPs , A: normal metaphase, B: ring chromosome C:c Dicentric and chromosome break (1000x).

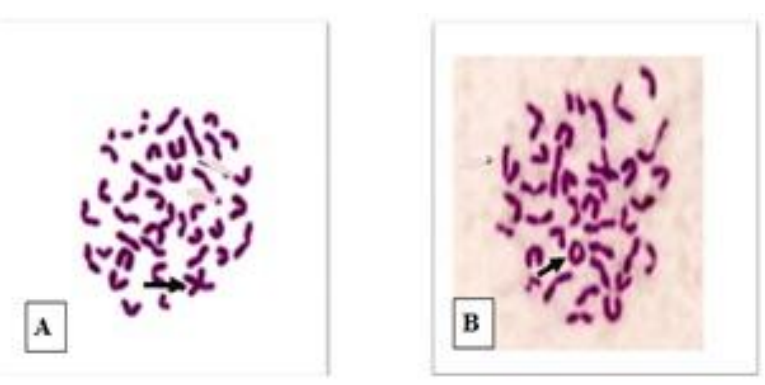

Figure (4): Metaphase of spleen cells of mice whom mothers were treated with steroid $0.068 \mathrm{mg} / \mathrm{kg} \mathrm{B}$ wt. of COCPs showing, A: centric fusion, B: ring chromosome (1000x).

\section{Discussion}

Our results showed that when the concentration of COCPs which was given to the pregnant mice increased the chromosomal aberration percentage in the bone marrow cells or spleen cells, that because the low concentration of chemical substance didn't have the ability to reach and effects in the incur molecules which is DNA and protein, although the low concentration have the ability to repair and repeat DNA structure very fast in low concentration but high concentration work on cripple this process [6,7]. The results showed that COCPs have the ability to induce chromosomal aberration in the bone marrow cells and spleen cells in the new generation belonged to mothers treated with this drug but little much from the results of the positive control, some researchers noted that 
norethisterone, which it is some kind of progesterone that used in COCPs can induce chromosomal aberration in the bone marrow cells [8].

The results shows that the mitomycin-C (MMC) reduce the mitotic index $\mathrm{MI}$ and induce chromosomal aberration $\mathrm{CA}$ on bone marrow and spleen cells, this reduction in $\mathrm{MI}$ resulted may be related to that MMC after biochemical activation react electron rich areas of susceptible molecules such as nucleic Acid and proteins $[9,10]$. The nuclease damage is responsible for the mutagenecity while the effect on proteins will further aggravate malfunction of the host cell [11]. These will lead to decrease (or not produce) the quantities of proteins required for mitosis, or the code did not reach the cells to induced it for proliferation, the drug may cause the death of bone marrow cells [12]. Study that it may be to defect accrued in the mitotic spindle composition during cell division. The increase of chromosomal aberrations CAs in bone marrow cells of treated mice with MMC agreed with [13, 14].

Some researcher consider synthetic steroid hormones as genotoxic agents, which can subscribe directly in DNA change [15,16], but other researcher suppose that hormones can act indirectly in oxidation of some substances of metabolism reaction which formed during metabolism $[17,18]$.

\section{References}

1. Burkman, R., Schlesselman, JJ. and Zieman, M. (2004). Safety concerns and health benefits associated with oral contraception. Am. J. Obstet. gynecol. 190:5-22.

2. Shubber, EK., Kram, D. and Williams, J. (1985). In vitro assay of cytogenetic damage induced in bone marrow cells in vivo by chemical carcinogens. Japan J. Med. Sci. Biol. 38:207-216.

3. Ahmad, E., Shadab, A., Hoda, A. and Afzal, M. (2000). Genotoxic effects of estradiol-17beta on human lymphocyte chromosomes. Mutat. Res. 466: 109-115.

4. Kayikcioglu, F., Gunes, M., Baltaci, V., Kocak, M., Alpas, I. and Haberal, A. (2000). Sister-chromatid exchange frequencies in postmenopausal hormone replacement patients. Muta. Res. 452: 37-39.

5. IARC, International Agency for Research on Cancer. (1999). Monograph on the evaluation of carcinogenic risk to humans. Hormonal contraception and postmenopausal hormone therapy. Lyon France.72: 49-338.

6. Sharma, AK. and Sharma, A. (1980). Chromosome analysis following short and long term cultures in animal, including man. In: chromosome techniques. $3^{\text {rd }}$ ed. Butterworth, London, Boston, Sydney, Wellington, Durban, Tokyo. Springer. Pp: 354.

7. Bukvic, N., Susca, F., Bukvic, D., Fanelli, M. and Guanti, G. (2000). 17- $\alpha$ ethynylestradiol and norgestrel in combination induce micronucleus increases and aneuploidy in human lymphocyte and fibroblast cultures. Terat. Carcinog. Mutagen. 20:147-159.

8. Liehr, JG. (2000). Isestradiol a genotoxic mutagenic carcinogen? Endocr. 21:4054.

9. Santen, RJ., Yue, W., Naftolin, F., Mor, G. and Berstein, L. (1999). The potential of aromatase inhibitors in breast cancer prevention. Endocr Relat Cancer. 6:235-243. 
10. Tsutsui, T., Tamura, Y., Yagi, E. and Barrett, JC. (2000). Involvement of genotoxic effects in the initiation of estrogen-induced cellular transformation: studies using Syrian hamster embryo cells treated with $17 \mathrm{~b}$-estradiol and eight of its metabolites. Int J Cancer. 86:8.

11. Siddique, YH. and M. Afzal. (2005). Genotoxic potential of cyproterone acetate: a possible role of reactive oxygen species. Toxicol. In vitro. 19: 63-68.

12. Siddique, YH., Beg, T. and Afzal, M. (2005). Genotoxic potential of ethinylestradiol in cultured mammalian cells. Chem Biol Interact. 151: 133-141.

13. Ahmed, E., Shadab, A., Azfer, M. and Afzal, M. (2001). Evaluation of genotoxic potential of synthetic progestins norethindrone and norgestrel in human lymphocytes in vitro. Mutat. Res. 494: 13-20.

14. Shyama, SK. and Rahiman, MA. (1993). Progestin (norethisterone) induced genetic damage in mouse bone marrow. Mutat. Res. 300:215-221.

15. Vijayalaxmi, KK. and Venu, R. (1999). In vitro anticlastogenic effects of L. Ascorbic acid in mice. Mutat. Res. 438: 47-51.

16. Al-Duliemy, DA. (2005). Anticlastogenicity and antileukaemia cell potencies of alcoholic extracts from grape (Vitis vinifera). M.Sc. thesis, College of Science, Baghdad University. Iraq. pp: 44-48.

17. AL-Awsee, ZSA. (2006). Cytological effects of Nigella sativa (black seed) callus extract on mouse bone marrow cells. M.Sc. thesis, College of Science. AL-Nahrain University. Iraq. pp: 47-49.

18. Liehr, JG. (1990). Genotoxic effects of estrogens. Mutation. Res. 238:269-276. 